\title{
MAKNA SEJARAH DAN BUDAYA DALAM SITUS JATIGEDE SUMEDANG
}

\author{
Oleh Dade Mahzuni
}

Fakultas Sastra Universitas Padjadjaran

Jln. Bandung-Sumedang Km 21 Jatinangor, Sumedang

Telepon: 022-7797205; Hp. 08156102603

e-mail: dade_mahzuni@yahoo.co.id

\begin{abstract}
Abstrak
Rencana pemerintah untuk membangun bendungan atau Waduk Jatigede tentunya akan membawa manfaat bagi masyarakat Sumedang khususnya dan Jawa Barat pada umumnya. Akan tetapi di balik manfaat dan keuntungan yang akan didapatkan dari pembangunan Waduk Jatigede tersebut, terdapat pula dampak negatifnya, yaitu berkaitan dengan keberadaan situs-situs sejarah yang terdapat di daerah setempat. Secara historis, situs-situs yang berada di daerah Jatigede dan sekitarnya, yang berjumlah sekitar 25 situs, merupakan peninggalan masa prasejarah (megalitikum) dan masa Kerajaan Tembong Agung atau Sumedang Larang. Oleh karena itu, keberadaan situs-situs tersebut memiliki arti dan nilai yang penting untuk pendalaman pengkajian sejarah kuno Jawa Barat.

Informasi arkeologis dan kesejarahan yang dikandung dalam situs-situs tersebut, baik secara tersurat mapun tersirat, mengandung makna bahwa masyarakat Jatigede dan sekitarnya, sejak awal keberadaannya sudah memiliki budaya yang mapan: masyarakat sudah hidup dengan pola menetap, memiliki pengetahuan dan pengalaman bercocok tanam dan membuat barang-barang keperluan rumah tangga dan keperluan hidup lainnya, mereka juga sudah memiliki kepercayaan animisme dan dinamisme. Selain itu, melihat arah dan posisi makam-makam pada sejumlah situs, menunjukkan makam Islam, tetapi dengan struktur makam berupa punden berundak. Hal ini menunjukkan telah terjadinya akulturasi budaya. Makna budaya pada situs juga tercermin dari cerita-cerita rakyat yang berkaitan dengan situs, yang di dalamnya mengandung nilai-nilai budaya dan sastra.

Apabila seluruh atau sebagian situs-situs yang berada di daerah Jatigede dan sekitarnya ditenggelamkan atau direlokasi ke tempat lain sejalan dengan pembangunan waduk Jatigede, maka makna dan nilai sejarah dan budayanya akan turut hilang atau berkurang. Hal ini disebabkan karena kesejarahan dan kebudayaan selalu berkaitan dengan tempat (site) dan benda-benda.
\end{abstract}

Kata kunci: situs Jatigede, makna sejarah dan budaya 


\section{Abstract}

The government plans to build a dam in Jatigede. This dam will be beneficial to the people of West Java, especially Sumedangians. On the other hand, the dam will have negative impacts on historical sites in the area. Jatigede has approximately 25 historical sites than spans from prehistoric period (megalithicum) to the time of Tembong Agung Kingdom or Sumedang Larang. These sites are very important to the study of ancient history of West Java.

From the historical and archaeological point of view, those sites inform us that the people of Jatigede developed a quite complex culture at that time: they lived sedentarily, and already had techniques and knowledge for cultivating lands. They also made household apparatus and any other equipments as well as developing beliefs in animism and dynamism. Their cemeteries show that there was acculturation between Islam (the orientation) and local beliefs (pyramidal structure). The folktales of the sites contain cultural and literary values.

If all the sites have to be drowned due to the construction of the dam, the historical meaning and values of them will be vanished forever.

Keywords: Jatigede site, cultural and historical meanings

\section{A. PENDAHULUAN}

Sumedang memiliki perjalanan sejarah yang sangat panjang. Berdasarkan data kesejarahannya, sebelum Indonesia merdeka, wilayah Sumedang pernah mengalami zaman prasejarah, zaman sejarah Sumedang kuno, zaman Kerajaan Sumedang Larang (1580 - 1620), zaman pengaruh Mataram (1620-1677), zaman Kompeni (1677 - 1799), zaman Pemerintah Hindia Belanda (1808 1942), dan zaman Pendudukan Jepang (1942 - 1945).

Sejak zaman Kerajaan Sumedanglarang sampai dengan zaman Pendudukan Jepang, tercatat ada 29 penguasa (raja dan bupati). Tiap zaman pemerintahan penguasa-penguasa itu meninggalkan jejak-jejak sejarahnya, baik berupa artefak (fakta berupa bendabenda) dan mentifak (fakta mental), maupun sosiefak (fakta sosial). Dari waktu ke waktu, fakta-fakta itu mengakumulasi menjadi memori kolektif dan sekaligus menjadi kebanggaan masyarakat daerah setempat.

Oleh karena itu, sisi apa pun dari masa lampau wilayah Sumedang, dalam besarannya masing-masing, memiliki makna penting bagi masyarakatnya, bahkan sebagian darinya masih cukup fungsional, sehingga keberadaan faktafakta masa silam itu terus dipelihara dan diabadikan. Salah satu jejak manusia masa lampau di daerah Sumedang adalah tempat-tempat yang termasuk kategori situs sejarah-budaya. Situssitus itu terdapat di daerah Jatigede dan sekitarnya.

Situs-situs itu - sebagian besar berupa makam - sampai sekarang masih sering diziarahi oleh masyarakat, baik yang berasal dari Sumedang maupun dari luar Sumedang. Masyarakat Sumedang umumnya dan para peziarah khususnya 
percaya, bahwa situs-situs itu merupakan tempat keramat. Sementara itu, di kalangan masyarakat Sumedang masih diselenggarakan upacara-upacara adat, yang secara kultural dan historis mengacu ke Sumedang pada masa silam.

Selanjutnya di daerah yang kaya akan situs sejarah dan budaya ini direncanakan akan dibangun bendungan besar yang disebut Waduk Jatigede. Rencana lokasi pembangunan bendungan itu terletak di Kampung Jatigede Kulon, Desa Cijeungjing, Kecamatan Jatigede Kabupaten Sumedang. Areal yang akan terkena genangan dan bangunan fasilitas bendungan seluas 4.896,22 ha (hektar) meliputi lima kecamatan dan 30 desa (sumber lain menyatakan 6 kecamatan dan 16 desa). Areal seluas itu untuk genangan 3.224,78 ha dan untuk fasilitas seluas 1.200 ha (Anonim, Tt). Keenam kecamatan dimaksud adalah Kecamatan Situraja, Cisitu, Darmaraja, Wado, Jatinunggal, dan Jatigede.

Keberadaan bendungan tersebut, paling tidak secara konseptual, akan memberi manfaat, baik bagi masyarakat Sumedang sendiri, bagi kabupatenkabupaten di sekitar Sumedang (Majalengka, Indramayu dan Cirebon), maupun bagi Pulau Jawa umumnya. Manfaat bagi masyarakat dan pemerintah Sumedang antara lain retribusi listrik, perikanan air tawar, pengairan untuk pertanian, dan pariwisata. Khusus untuk wilayah Pantura Jawa Barat (Kabupaten Majalengka, Indramayu dan Cirebon), keberadaan Waduk Jatigede akan dapat mengatasi kekeringan pada musim kemarau dan mengendalikan banjir pada musim hujan. Waduk Jatigede pun dapat mengkontribusi pembangkit tenaga listrik.
Akan tetapi, di balik manfaat dan keuntungan yang akan didapatkan dari pembuatan Waduk Jatigede, terdapat pula dampak negatif, di antaranya dampak negatif yang berkait dengan situs-situs sejarah dan cagar-cagar budaya di daerah setempat. Situs-situs yang ada di wilayah tersebut merupakan peninggalan masa lampau Sumedang, yaitu masa prasejarah dan masa Kerajaan Tembong Agung/ Sumedanglarang. Sebagian dari situs itu diduga makam leluhur pendiri desa. Secara kuantitatif lebih dari 25 situs akan terendam air, yang berarti situs-situs itu akan punah.

Berdasarkan penelitian arkeologi, peninggalan-peninggalan leluhur itu, memperlihatkan adanya transformasi dari masa prasejarah (masa sebelum dikenal tulisan) ke masa sejarah (masa setelah dikenal tulisan). Situs yang memiliki menhir/batu-batu besar (budaya megalit) adalah warisan prasejarah yang terus difungsikan pada masa sejarah (Lubis, $\mathrm{Tt}$ ). Meskipun nilai sejarah situs-situs tersebut belum diketahui secara jelas, karena sumber-sumbernya, khususnya sumber tertulis, sangat langka, namun situs-situs itu juga memiliki nilai penting lain, yaitu nilai budaya yang telah berlangsung secara turun-temurun dari generasi ke generasi. Oleh karena itu, di kalangan masyarakat, khususnya masyarakat yang memiliki ikatan emosional dan historis dengan situs, muncul pernyataan "selamatkan situssitus yang ada di daerah genangan!"

Perbedaan kepentingan antara dua pihak (pemerintah dan masyarakat) yang berkaitan dengan daerah situs tersebut, perlu dicarikan solusi yang akomodatif, yang dapat menguntungkan semua pihak. Hal itulah yang melatarbelakangi 
penelitian ini dilakukan. Adapun tujuan penelitian ini adalah:

Mengidentifikasi situs-situs di Jatigede.

Menjelaskan makna sejarah dan budaya dari situs-situs yang ada di daerah Jatigede.

Masalah yang diteliti menyangkut permasalahan sejarah dan budaya ${ }^{1}$, maka penelitian ini dilakukan dengan menggunakan Metode Sejarah dan Metode Antropologi. Metode Sejarah meliputi empat tahapan kerja, yaitu heuristik (mengumpulkan sumber), kritik (menyeleksi sumber), interpretasi (menafsirkan sumber), dan historiografi (menuliskan laporan). Sedangkan Metode Antropologi meliputi pengamatan lapangan dan wawancara mendalam.

\section{B. HASIL DAN BAHASAN}

\section{Data Arkeologi Situs}

Secara etimologis, kata/istilah situs berasal dari bahasa Inggris, site (bentuk jamaknya sites). Artinya adalah sebuah areal atau sebidang tanah di mana terdapat "sesuatu" yang berharga (an area or piece of land where something was). Undang-Undang Nomor 5 Tahun 1992 tentang Benda Cagar Budaya menyatakan:

"Situs adalah lokasi yang mengandung atau diduga mengandung benda cagar budaya termasuk

1 Dalam tulisan ini, budaya diartikan sebagai sistem pengetahuan (kognisi). Menurut Keesing (1997:8), budaya suatu masyarakat terdiri atas segala sesuatu yang harus diketahui atau dipercayai seseorang agar dia dapat berperilaku dalam cara yang dapat diterima oleh anggota-anggota masyarakat. lingkungannya yang diperlukan bagi pengamanannya" (Pasal 1 ayat 2).

Berdasarkan pengertian tersebut, maka pada sebutan "situs" terkandung dua makna; pertama adalah "tempat", kedua adalah "benda". Baik tempat maupun benda dalam cakupan situs, terkait dengan konteks sejarah. Bila salah satu dari kedua hal itu atau keduanya musnah, atau bendanya dipindahkan, maka nilai sejarahnya menjadi berkurang atau bahkan hilang.

Hasil penelitian lapangan menunjukkan, situs Jatigede terdiri atas makam, petilasan, dan mata air. Sebagian besar situs tersebut berupa makam kuno. Dalam pembagian wilayah administratif sekarang, situs-situs itu tersebar di empat daerah kecamatan: Darmaraja, Jatigede, Jatinunggal, dan Wado. Beberapa situs hasil penelitian arkeologi, dan keterangan ringkasnya adalah sebagai berikut.

\section{1) Situs Cipeueut}

Situs Cipeueut atau dikenal pula dengan sebutan Astana Cipeueut, terletak di Kampung Cipeueut, Desa Cipaku, Kecamatan Darmaraja. Bagian yang teramati terdiri atas bangunan berbentuk empat persegi panjang yang dibatasi oleh pagar batu setinggi $20 \mathrm{~cm}$. Pada bagian tengah atas (sisi panjang) terdapat lingga (semu) dan di depan lingga diletakkan batu datar (tempat sesaji). Batuan penyusunnya terdiri dari batu kali.

\section{2) Situs Astana Gede}

Situs ini berada di Kampung Astana Gede, Desa Cipaku, Kecamatan Darmaraja. Situs ini berupa bangunan teras berundak terdiri atas tiga teras. Teras paling atas berukuran lebih kecil, terdapat makam Embah Jalul, dan dua teras berikutnya terdapat makam Dalem 
Prabu Lembu Agung, dan makam Embah Dalem Demang Cipaku. Lingga (semu), menhir atau batu tegak berbentuk kubus dengan atap berbentuk trapesium diletakkan pada bagian utara permukaan puncak punden.

\section{3) Situs Sawah Jambe}

Situs Sawah Jambe terletak di Kampung Sawah Jambe, Desa Leuwihideung, Kecamatan Darmaraja. Di Situs Sawah Jambe ditemukan bangunan teras berundak pada lahan seluas $15 \times 25$ meter, yang dibangun mengikuti kontur bukit. Pada teras teratas ditemukan empat menhir dalam posisi rebah, di bawah teras pada bagian sisi selatan terdapat teras yang dibatasi susunan batu.

\section{4) Situs Tanjungsari}

Situs Tanjungsari berada di tepi sebelah barat Sungai Cimanuk, di Dusun Kebontiwu, Desa Cibogo, Kecamatan Darmaraja. Di situs ini terdapat bangunan berundak berupa tatanan batu yang membentuk teras-teras. Sekarang bangunan teras berundak itu merupakan komplek makam kuno. Areal situs yang berisi sejumlah makam, dikelilingi oleh parit. Sebagian besar makam dipercaya sebagai makam keturunan Raja Tembong Agung.

\section{5) Situs Pasir Limus}

Situs Pasir Limus terletak di Kampung Pasir Limus, Desa Leuwihideung, Kecamatan Darmaraja. Situs ini berupa bangunan teras berundak yang berada di atas puncak bukit dengan luas teras teratas $35 \times 20$ meter dan luas teras terbawah $50 \times 35$ meter. Sekarang ini bangunan teras berundak dijadikan makam keramat. Makam-makam yang dianggap sebagai makam tokoh yang berhubungan dengan leluhur masyarakat Sumedang di antaranya: Makam Embah Dalem Jamanggala, Makam Nyi Mas Ratna Komala Inten, Makam Eyang Dipa, Eyang Dipawangsa, dan Eyang Mananti, serta makam Eyang Jayaperkasa (Eyang Nanti) atau disebut juga Petilasan Tilem.

\section{6) Situs Nangkod}

Situs Nangkod terletak di Kampung Nangkod, Desa Leuwihideung, Kecamatan Darmaraja. Situs berupa bangunan teras berundak. Struktur batu yang masih tampak jelas sekarang ini adalah struktur di sisi utara, sedangkan struktur sisi barat, selatan, dan timur sudah terputus-putus. Pada teras berundak itu terdapat komplek makam yang berjajar dari barat ke timur, menhir, dan sebaran batu alam. Makam hanya ditandai oleh dua batu alam berorientasi utara selatan. Lahan inti kelompok makam ini dibatasi oleh susunan batu alam yang masih tampak di sisi utara, barat dan timur. Menurut informasi lisan, antara lain dari kuncen, makam di komplek itu antara lain makam Embah Janggot Jaya Perkosa dan kerabatnya. Kedua tokoh itu dipercaya memiliki kesaktian dan mereka adalah pendiri kampung.

\section{7) Situs Munjul}

Situs ini terletak di sebuah bukit kecil, di sebelah selatan dan barat jalan di Kampung Munjul, Desa Sukamenak, Kecamatan Darmaraja. Situs Munjul adalah bangunan teras berundak dan merupakan komplek makam. Salah satu makam yang berada di puncak teras bangunan berundak adalah makam Singadepa. Di sebelah barat makam, terdapat makam-makam kuno lain dengan jirat terbuat dari semen dan nisan berupa menhir (batu alam). Di bagian selatan 
makam terdapat undakan-undakan batu alam.

\section{8) Situs Ciwangi}

Situs ini berada di sebelah barat Situs Tanjungsari, tepatnya di lingkungan pemukiman penduduk Kampung Ciwangi, Desa Cibogo, Kecamatan Darmaraja. Situs Ciwangi berupa komplek makam kuna yang dianggap keramat. Menurut cerita rakyat setempat, makam utama di situs itu adalah makam Mbah Buyut Mandor Sora, pendiri Dusun Ciwangi. Komplek makam berbentuk bujursangkar dengan teras batu alam. Di sana terdapat empat nisan berupa menhir, terbagi atas masing-masing dua nisan di sisi barat dan sisi timur, berorientasi utara - selatan.

\section{9) Situs Betok}

Situs Betok terletak di Kampung Betok, Desa Leuwihideung, Kecamatan Darmaraja. Di situs ini terdapat tiga makam kuno. Pada sudut barat laut terdapat dua makam yang jiratnya menyatu yaitu makam Nanggapati dan Bogapati. Makam itu berorientasi utara - selatan. Kedua tokoh itu dipercaya oleh masyarakat setempat sebagai perintis pembukaan Kampung Betok.

\section{0) Situs Muhara}

Situs Muhara terletak di Kampung Muhara, Desa Leuwihideung, Kecamatan Darmaraja. Di dalam lingkungan itu terdapat makam Eyang Narapati dan Eyang Martapati. Makam Eyang Narapati terletak di sisi barat lahan. Jirat makam berupa tatanan batu berdenah empat persegi panjang. Nisan terbuat dari batu alam (menhir). Makam Eyang Martapati berada di sisi timur makam Eyang Narapati berjarak sekitar 20 meter. Jirat berupa struktur batu berdenah empat persegi panjang, dengan nisan terbuat dari batu alam.

\section{1) Situs Lameta}

Situs ini berada di Kampung Lameta, Desa Leuwihideung, Kecamatan Darmaraja. Di situs tersebut terdapat dua makam kuno yang terletak berdampingan, yaitu makam Eyang Dira dan putranya, Eyang Toa, dengan jarak 2,6 m. Menurut cerita rakyat, Eyang Dira dan Eyang Toa adalah penjaga sungai Ciliwung dan Cisadane. Mereka juga dipercaya sebagai pangeran Jayakarta. Katanya, hal yang disebut terakhir berpengaruh pada sejumlah peziarah untuk melakukan usaha di Jakarta.

\section{2) Situs Nangewer}

Situs ini terletak di Kampung Nangewer, Desa Leuwihideung, Kecamatan Darmaraja. Situs berada di lingkungan pohon bambu yang sekarang dijadikan pemakaman umum. Pada situs itu terdapat makam Eyang Wangsa Wacana. Makam ini dipagar dengan tembok setinggi $90 \mathrm{~cm}$, yang telah rubuh pada sisi barat dan timurnya. Luas lahan berpagar berukuran 3,5 x 4 meter. Penanda makam berusa nisan terbuat dari batu alam berdiameter $20 \mathrm{~cm}$ setinggi $22 \mathrm{~cm}$.

\section{3) Situs Leuwiloa}

Situs Leuwiloa berada di Kampung Leuwiloa, Desa Leuwihideung, Kecamatan Darmaraja. Situs berupa makam kuno yang sekaligus dijadikan pemakaman umum. Makam tersebut berada di tengah-tengah komplek makam, berpagar tembok, berdenah segi empat dengan jirat terbuat dari bata berplester 
dan nisan terbuat dari batu alam. Di bawah jirat terlihat jejak tatanan batu.

\section{4) Situs Tembong Agung}

Situs Kerajaan Tembong Agung terletak di Kampung Muhara, Desa Leuwihideung, Kecamatan Darmaraja. Situs ini berada pada kawasan seluas dua hektar yang diduga bekas lahan Kerajaan Tembong Agung. Kawasan itu diapit oleh dua aliran sungai, yaitu Sungai Cihonje dan Sungai Cimanuk.

\section{5) Situs Marongpong}

Situs ini berada di daerah Desa Leuwihideung, Kecamatan Darmaraja. Di situs ini terdapat dua makam bercorak megalitik dengan orientasi utara-selatan. Makam berada di atas bukit berdekatan dengan pemukiman. Kedua makam itu dipercaya oleh masyarakat setempat sebagai makam Embah Sutadiangga dan Embah Jayadiningrat. Di kalangan masyarakat setempat,Embah Sutadiangga dan Embah Jayadiningrat dipercaya sebagai tokoh di Kerajaan Tembong Agung dan penyebar agama Islam di daerah Darmaraja.

\section{6) Situs puncak Damar}

Situs ini terletak di Kampung Cisema, Desa Pakualam, Kecamatan Darmaraja. Situs berupa komplek makam, di antaranya tiga makam keramat yaitu makam-makam Buyut Maja, Embah Entol (Tatang Jalak), dan Suta Derepa. Makam-makam tersebut terletak di dataran tinggi di sebuah punggung bukit. Makam Embah Entol berbentuk persegi panjang dengan susunan batu alam berbentuk persegi, berorientasi utaraselatan. Makam berukuran 180 x $100 \mathrm{~cm}$, dan tidak bernisan. Tokoh ini dipercaya sebagai pendiri Desa Pakualam.

\section{7) Situs Astana Leutik}

Situs Astana Leutik terletak di Kampung Pakualam, Desa Pakualam, Kecamatan Darmaraja. Tinggalan di situs ini berupa lima makam tokoh, yaitu Embah Demang Suradinata, Embah Demang Suradimanggala, Embah Demang Raksamanggala, Embah Demang Wargadinata, dan Embah Demang Aria Mangkunegara, berjajar ke arah timur. Dua makam yang masih terlihat bentuknya adalah makam Demang Suradinata dan makam Demang Raden Wargadinata.

\section{8) Situs Gunung Penuh}

Situs ini terletak pada sebuah bukit di sebelah barat aliran Sungai Cialing, Kampung Bantarawi, Desa Padajaya, Kecamatan Wado. Diduga dahulu kawasan itu berupa punden berundak. Menurut kuncen, dua makam yang terletak di teras teratas adalah makam Eyang Tresna Putih, yang dikenal dengan sebutan Eyang Haji Payung Jagat dan istrinya Nawang Sasih. Eyang Tresna Putih alias Eyang Haji Payung Jagat dan istrinya dipercaya oleh masyarakat setempat masih keturunan raja Pajajaran.

\section{9) Situs Eretan}

Situs Eretan berada di Kampung Cisurat, Desa Cisurat, Kecamatan Wado. Situs itu disebut juga makam Embah Geulis, istri dari Prabu Gajah Agung. Makamnya ditandai oleh dua batu alam sebagai nisan, berorientasi utara selatan, dikelilingi pagar besi. Di situs tersebut juga ada sejumlah makam tua lainnya yang tidak teridentifikasi. Sebuah makam bercirikan Islam dengan batu 
nisan bertuliskan huruf Arab beraksara Pegon.

\section{0) Situs Cibuntu}

Situs Cibuntu terletak di Kampung Cisurat, Desa Cisurat, Kecamatan Wado. Tinggalan di situs ini berupa sebuah makam yang diyakini sebagai makam Embah Jaga Riksa. Bangunan tempat perziarah melakukan ritual terletak di sisi kolam berukuran 10 x 5 meter.

\section{1) Situs Tulang Gintung}

Situs Tulang Gintung berlokasi di Pasir Leutik, Kampung Sundulan, Desa Padajaya, Kecamatan Wado. Tinggalan di situs ini berupa makam Haji Rarasakti (Jayasakti) yang terletak di atas bukit. Makam tidak dilengkapi jirat, berorientasi utara-selatan, dengan nisan batu andesit setinggi $\pm 20 \mathrm{~cm}$. Makam diberi selasar dari keramik berwarna putih dengan ukuran 30 x $30 \mathrm{~cm}$. Luas batas selasar $3,15 \times 4,12$ meter, dengan luas makam inti $2,4 \times 1$ meter.

\section{2) Situs Cipawenang}

Situs ini terletak di Kampung Cigangsa, Desa Pawenang, Kecamatan Wado. Tinggalan di situs ini berupa mata air yang terletak di sebuah bukit dengan ketinggian 245 meter dpl. Mata air tersebut tidak pernah kering walaupun musim kemarau panjang. Mata air dibatasi batu andesit dengan bentuk relatif persegi. Bentang lahan situs melingkar dengan luas sekitar 25 x 20 meter, dengan sebaran batuan dan beberapa menhir.

\section{3) Situs Cigangsa}

Situs ini berada pada sebuah bukit di sebelah timur situs Cipawenang, tepatnya di Kampung Cigangsa, Desa
Pawangan, Kecamatan Wado. Situs Cigangsa merupakan komplek makam Islam. Makam utama yang terletak di tengah adalah makam Embah Dalem Raden Arya Wangsa Dinaya. Pada batu nisan (batu pasiran) berbentuk kurawal, terdapat angka tahun $1247 \mathrm{H} / 1848 \mathrm{M}$. Pada bagian nisan tertulis huruf Arab yang kini sudah pudar. Di kanan dan kiri makam utama terdapat terdapat dua makam pendamping yang belum teridentifikasi.

\section{4) Situs Sumur Mas}

Situs ini berada di Kampung Cadas Ngampar, Desa Sukakersa, Kecamatan Jatigede. Tinggalan berupa sumur berdiameter $\pm 2,5$ meter dengan kedalaman $50 \mathrm{~cm}$. Saat ini sumur tersebut berdinding tembok.

\section{5) Situs Sabelit}

Situs Sabelit berlokasi di Desa Jemah, Kecamatan Jatigede. Pada bagian lahan yang landai terdapat makam Raden Pungut. Makam itu berada pada bentang alam berupa lereng yang berbatasan dengan sawah, ladang tembakau dan tebing bukit. Makam ini ditandai oleh jirat dari batuan alam berukuran 1,8 x 2 meter, berorientasi ke utara-selatan. Nisan kepala berupa batu alam.

\section{6) Situs Cadas Ngampar}

Situs Cadas Ngampar berada di Kampung Cadas Ngampar, Desa Sukakersa, Kecamatan Jatigede. Di situs ini terdapat empat makam yaitu makam Aki dan Nini Angkrih serta Aki Kulo dan Nini Kulo. Nisan makam dari batu monolit berdiameter $30 \mathrm{~cm}$ dengan tinggi 20-41 cm. Setiap nisan dibatasi oleh susunan batu bata baru setinggi selapis bata. Makam berorientasi ke utara - 
selatan dan berderet dari timur ke barat. Di sekitar makam terdapat kompleks pemakaman umum yang berlanjut sampai sekarang.

\section{Makna Sejarah}

Keberadaan situs-situs di daerah Jatigede dan sekitarnya, tentu tidak dapat dipisahkan dari zaman-zaman yang dilalui oleh masyarakat di daerah itu. Data kesejarahan mengenai daerah itu berikut data situsnya mengindikasikan, bahwa Jatigede dan sekitarnya menjadi daerah pemukiman penduduk sejak zaman prasejarah, paling tidak sejak zaman megalitikum. Hal itu berarti pemukiman tersebut sudah berusia sangat tua.

Data tentang situs-situs tersebut, ditunjang oleh sumber tradisional dan cerita rakyat, memiliki arti penting sebagai bahan pengetahuan sejarah lokal Sumedang, khususnya bagi masyarakat daerah setempat. Hal itu disebabkan situs-situs tersebut merupakan peninggalan manusia dari tiga zaman yang berkesinambungan, yaitu: zaman prasejarah, zaman kerajaan (Hindu dan Islam), dan zaman awal perkembangan kabupaten.

Data situs dan informasi dalam cerita rakyat yang menyangkut sejarah lokal Sumedang adalah data mengenai pemerintahan Kerajaan Tembong Agung, masuk dan berkembangnya agama Islam di daerah Darmaraja dan sekitarnya, data yang menyangkut Kerajaan Sumedang Larang, data menyangkut Kabupaten Sumedang masa pemerintahan Pangeran Kornel (Pangeran Kusumadinata), dan lain-lain.

Bila di daerah tersebut memang benar pernah eksis Kerajaan Tembong Agung dengan pusat pemerintahan di
Darmaraja ${ }^{2}$, berarti kerajaan itu adalah kerajaan kecil bawahan Kerajaan Sunda (runtuh tahun 1579/1580). Hal itu berarti daerah Darmaraja dan sekitarnya, merupakan daerah yang memiliki kedudukan penting dalam pemerintahan kerajaan yang kemudian berlanjut dengan pemerintahan kabupaten, yakni Kabupaten Sumedang. Kabupaten ini berdirisejaktahun 1620, bukansejaktahun 1578, seperti diberitakan dalam beberapa sumber. Bila hal ini dihubungkan dengan keberadaan sejumlah makam dalem di beberapa situs, boleh jadi makam itu adalah makam sebagian bupati Sumedang abad ke-18 hingga abad ke-19.

Keberadaan beberapa batu nisan yang berangka tahun 1835, 1878, 1890 dan lain-lain di Situs Tanjungsari Kecamatan Darmaraja, mengandung arti makam-makam Islam itu mulai ada ketika Sumedang sudah berkedudukan sebagai kabupaten di bawah penjajahan Belanda. Angka-angka tahun itu penting artinya untuk melacak peristiwa atau situasi dan kondisi daerah yang bersangkutan pada sekitar tahun-tahun tersebut.

Secara umum, keberadaan situssitus tersebut mencerminkan perjalanan sejarah daerah setempat dari zaman Megalithikum(prasejarah)sampaidengan abad ke-19, secara berkesinambungan. Data itu memiliki arti dan nilai penting untuk pendalaman pengkajian sejarah kuno Jawa Barat.

Keberadaan situs-situs berupa makam Islam juga merupakan data sejarah, bahwa pemukiman di daerah Jatigede boleh jadi muncul dan

2 Dari segi toponimi (asal-usul nama tempat), Darmaraja mengindikasikan bahwa tempat itu pernah menjadi pusat kegiatan raja/kerajaan. 
berkembang sejalan dengan masuk dan berkembangnya agama Islam di wilayah Sumedang, termasuk Jatigede. Beberapa sumber sejarah Jawa Barat menginformasikan, bahwa agama Islam masuk ke daerah Sumedang melalui penyebaran dari Kerajaan Cirebon yang diperintah oleh Syarif Hidayatullah (Sunan Gunung Jati). Diduga perkembangan pemukiman dan agama Islam di daerah Jatigede, terutama terjadi setelah di wilayah Sumedang berdiri kerajaan, khususnya Kerajaan Sumedang Larang (1580 - 1620).

Di Situs Cipeueut, Desa Cipaku Kecamatan Darmaraja terdapat tiga buah makam kuno. Masyarakat setempat percaya betul, bahwa ketiga makam itu masing-masing adalah makam Prabu Guru Aji Putih, makam Nyi Mas Ratu Inten (Nyi Mas Dewi Nawangwulan), dan makam Sanghiang Resi Agung. Mereka adalah raja dan tokoh penting Kerajaan Tembong Agung, cikal-bakal Kerajaan Sumedang Larang. Seperti telah disebutkan, keberadaan Kerajaan Tembong Agung hanya diinformasikan dalam sumber tradisional. Sampai saat ini belum ditemukan sumber sejarah akurat yang memuat informasi tentang Kerajaan Tembong Agung. Sebaliknya, informasi tentang eksistensi Kerajaan Sumedang Larang termuat dalam beberapa sumber sejarah Jawa Barat, bahkan dalam dokumen kolonial Belanda.

Pada Situs Astana Gede di Kecamatan Darmaraja dan Situs Curug Emas di Kecamatan Jatigede, terdapat makam dengan tokoh yang dimakamkannya disebut prabu. Data itu menunjukkan bahwa kedua situs tersebut adalah tempat dipusarakannya raja, karena prabu adalah sebutan untuk raja. Hal ini tentu berkaitan dengan informasi dari sumber tradisional, bahwa Darmaraja pernah menjadi pusat Kerajaan Tembong Agung. Bila informasi itu benar, berarti kerajaan tersebut merupakan cikal-bakal Kerajaan Sumedang Larang. Keberadaan kerajaan yang disebut terakhir jelas dinyatakan dalam berbagai sumber sejarah yang akurat.

Pada kedua situs tersebut juga terdapat sejumlah makam dengan tokoh yang dimakamkannya disebut dalem. Makam dalem juga terdapat di Situs Tanjungsari dan Pasir Limus. Keberadaan sejumlah makam dalem, merupakan data yang menunjukkan bahwa daerah Jatigede adalah salah satu tempat pemakaman bupati, karena dalem adalah sebutan untuk bupati tempo dulu (abad ke-17 hingga awal abad ke20). Hal itu diperkuat pula oleh adanya makam Raden Aria Sutadinata di Situs Gagak Sangkur, Dusun Sundulan, Desa Padajaya, Kecamatan Wado. Aria adalah salah satu gelar tradisional yang berkaitan dengan kedudukan/jabatan bupati tempo dulu. Gelar Aria digunakan oleh bupati paling tidak sampai dengan zaman pemerintahan Hindia Belanda (18081942). Data sejarah lainnya adalah batu nisan bertulisan Arab gundul (Pegon) dan Jawa, berangka tahun 1835, 1878, 1890 dan lain-lain.

Pada situs-situs tersebut dan beberapa situs lainnya terdapat pula makam dengan tokoh yang dimakamkannya disebut embah, eyang, buyut, haji, dan kuwu. Misal, makam Embah Janggot Jaya Perkosa di Situs Nangkod, Dusun Nangkod, Desa Leuwihideung, Kecamatan Darmaraja; makam Eyang Dipawangsa di Situs Pasir Limus, Kampung Pasir Limus, Desa Leuwihideung, Kecamatan Darmaraja; makam Embah Buyut Mandor, makam 
keramat di Dusun Ciwangi, Desa Cibogo, Kecamatan Darmaraja; makam Eyang Haji Abdul Saka di Situs Nangewer, Dusun Nangewer, Desa Leuwihideung, Kecamatan Darmaraja, dan lain-lain. Keberadaan makam Eyang Haji Abdul Saka merupakan data yang memperkuat, bahwa makam-makam di situs-situs tersebut adalah makam Islam.

Selain itu terdapat pula makam dengan nama-nama tokoh. Berdasarkan namanya, tokoh-tokoh itu diduga adalah tokoh penting di lingkungan kerajaan dan masyarakat. Makam Kuwu Manten di Situs Lontong, Dusun Lontong, Desa jemah, Kecamatan Jatigede, mengindikasikan bahwa tokoh yang dimakamkan adalah pejabat pemerintahan desa. Dulu, kuwu adalah sebutan untuk kepala desa di daerah Jawa Barat, khususnya di Priangan.

\section{Makna Budaya}

Data arkeologi dan kesejarahan yang dimiliki oleh situs, baik secara tersurat maupun tersirat, mengandung makna bahwa masyarakat Jatigede dan sekitarnya, sejak awal keberadaannya sudah memiliki budaya yang mapan, yaitu budaya zaman Megalithikum. Di daerah Jatigede, budaya zaman itu ditunjukkan oleh keberadaan menhir dan punden berundak. Menurut Von Heine Geldern, menhir dan punden berundak merupakan budaya megalitik tua yang menyebar ke Indonesia pada zaman Neolithikum (2500-1500 SM), dibawa oleh manusia ras Proto Melayu, pendukung kebudayaan kapak persegi.

Pada zaman Megalithikum, masyarakat sudah hidup dengan pola menetap dan tinggal di rumah sederhana. Mereka sudah memiliki pengetahuan dan pengalaman bercocoktanam dan sudah pandai membuat barang-barang keperluan rumah tangga dan keperluan hidup lainnya. Selain itu mereka juga sudah memiliki kepercayaan, yaitu animisme dan dinamisme. Dalam kepercayaan itulah kaitan menhir dan punden berundak, yaitu sebagai sarana pemujaan terhadap roh nenek moyang. Kedua sarana itu dianggap sebagai bangunan yang suci.

Telah disebutkan bahwa berdasarkan arah atau posisinya, makammakam pada sejumlah situs di daerah Jatigede dan sekitarnya merupakan makam Islam. Namun struktur makam itu berupa punden berundak. Pola struktur punden berundak merupakan pola baku dari tradisi megalitik yang banyak dijumpai di Jawa Barat dan Lampung. Hal itu mencerminkan bahwa budaya megalitik, disadari ataupun tidak, diserap oleh masyarakat muslim. Dengan kata lain, terjadi akulturasi budaya. Memang pada tahap awal penyebaran agama Islam di Jawa Barat, para penyebar agama itu dengan bijaksana melakukan islamisasi masyarakat melalui tradisi masyarakat daerah setempat.

Makna budaya pada situs juga tercermin dari cerita-cerita rakyat yang berkaitan dengan situs, baik situs berupa makam yang dianggap keramat maupun tempat yang dianggap mengandung unsur magis. Cerita-cerita rakyat tersebut baru sebagian kecil yang sudah diperoleh, antara lain sebagai berikut.

\section{1) Cerita Prabu Aji Putih}

Menurut cerita turun-temurun, Prabu Aji Putih adalah tokoh pendiri Kerajaan Tembong Agung dengan keraton berlokasi di Kampung Muhara, Cihideung. Ia beristrikan Dewi Ratna 
Inten alias Dewi Nawang Wulan, putri Jagat Jayanta/keponakan Purbasora.

Cerita selanjutnya adalah proses Prabu Aji Putih memeluk agama Islam. Mula-mula Prabu Aji Putih bermimpi bertemu dengan seorang kiai berparas tampan dan berwibawa. Kiai itu memberi petunjuk, bahwa negara akan terhindar dari mara bahaya dan bencana, apabila raja mendapatkan "bintang kerti". Untuk memahami petunjuk itu, Prabu Aji Putih kemudian melakukan semedi. Hasilnya ia mengetahui bahwa agama terakhir (Islam) diturunkan di Mekah. Oleh karena itu ia harus datang ke tempat tersebut.

Setelah menyerahkan kekuasaan/ pemerintahan kepada putra yang sulung, yaitu Bratakusumah (Tajimalela), Prabu Aji Putih dengan ilmu "Rasjleg"3 datang ke Teluk Persi. Di sana ia bertemu dengan seorang ulama besar bernama Syekh Ali. Ulama itu bersedia menjadi guru Prabu Aji Putih dalam ilmu agama Islam, dengan syarat Prabu Aji Putih terlebih dahulu harus membaca kalimah shahadat sebagai tanda pemeluk agama Islam. Untuk menyempurnakan keislamannya, Prabu Aji Putih menunaikan ibadah haji di Mekah dan mendapat gelar Haji Purwa Darmaraja. Prabu Aji Putih mendapat perintah dari gurunya, agar di tempat asalnya ia harus menyebarkan agama Islam. Untuk kepentingan ibadah, ia harus mendirikan masjid dan tempat wudlu di tujuh tempat.

Setelah Prabu Aji Putih kembali ke Darmaraja, ia segera melaksanakan perintah gurunya. Ia berupaya untuk membangun masjid di daerah kaki Gunung Lingga. Namun upaya itu

$3 \quad$ Ketika pikiran ingat pada tempat yang ingin dituju, seketika itu juga pemilik itu sudah berada di tempat yang dituju. gagal, karena mendapat penolakan bahkan pelecehan dari penduduk yang belum mengetahui kegunaan masjid. Untuk mengenang peristiwa itu, Prabu Aji Putih mengganti nama Gunung Lingga menjadi Gunung Masigit. Prabu Aji Putih berhasil membangun tempattempat wudlu di enam sumber mata air, yaitu di Cikajayaan, Cikahuripan, Cikawedukan, Cikatimbulan, Cimaraja, dan Cilemahtama.

Prabu Aji Putih kemudian membangun padepokan (pesantren) di Cipeueut dan ia menetap di sana. Nama Cipeueut diganti menjadi Cipaku. Namun alasan pergantian nama itu tidak diceritakan.

Dalam perkembangannya, santrisantri di pesantren itu bukan hanya penduduk Sumedang, tetapi banyak pula yang berasal dari daerah lain. Dalam mengajarkan ajaran Islam, Prabu Aji Putih antara lain memperkenalkan "Falsafah Alip" sebagai simbol keesaan Tuhan (Allah SWT). Bila huruf alip diberi tanda baca menjadi A - I - U, maka A berarti akal, I berarti iman, dan U berarti usaha/upaya. Falsafah itu oleh Prabu Aji Putih juga digunakan sebagai ciri orang Cipaku yang disimbolkan dalam batu nisan. Orang Cipaku yang meninggal, batu nisan pada kuburnya harus tunggal (Alif juga bermakna satu).

Cerita tersebut mengandung arti bahwa semula penduduk Darmaraja tidak memeluk agama Islam. Pengislaman penduduk di daerah itu dimulai oleh pengislaman Prabu Aji Putih selaku penguasa daerah. Selanjutnya Prabu Aji Putih menjadi tokoh penyebar agama/ ajaran Islam melalui Pesantren Cipeueut (Cipaku). 


\section{2) Cerita Dewi Nawang Wulan}

Diceritakan bahwa Dewi Nawang Wulan, putri Jagat Jayanta, terah (turunan) ménak (bangsawan) Galuh, adalah putri cantik jelita yang pandai nembang (bernyanyi) dan menari. Ia sering bermimpi bertemu dengan jejaka ganteng keturunan raja. Oleh karena itu, walaupun ada saudagar dari Galuh yang melamarnya, ia menolak lamaran itu. Dewi Nawang Wulan percaya bahwa mimpinya bakal menjadi kenyataan.

Singkat cerita, mimpi Dewi Nawang Wulan menjadi kenyataan. Suatu hari tiba-tiba datang Prabu Aji Putih melamar Dewi Nawang Wulan. Sang Dewi menerima lamaran itu, karena Prabu Aji Putih memang laki-laki yang sering bertemu dalam mimpinya.

Bila dihubungkan dengan cerita Prabu Aji Putih, cerita itu menunjukkan bahwa Prabu Aji Putih menikah dengan Dewi Nawang Wulan alias Nyi Mas Ratu Inten, jauh sebelum Prabu Aji Putih memeluk agama Islam.

\section{3) Cerita Prabu Tajimalela}

Prabu Tajimamlela semula bernama Bratakusumah. Ia adalah putra sulung Prabu Aji Putih dari Dewi Nawang Wulan alias Nyi Mas Ratu Inten.

Jauh sebelum menggantikan ayahnya sebagai raja, Bratakusumah meninggalkan keraton untuk mencari ilmu, sebagai bekal untuk menjadi pemimpin. Ia berguru kepada Resi Cakra Sakti yang tinggal di kaki Gunung Cakrabuana.

Setelah sekian lama berguru, Bratakusumah diperintahkan oleh gurunya untuk bertapa di Gunung Nurmala selama 21 hari 21 malam. Hal itu dimaksudkan agar ia memiliki wibawa dan kekuatan lahir-batin untuk memimpin rakyat. Menjelang akhir waktu bertapa, dari langit turun sinar merah berkelok-kelok seperti selendang tertiup angin menuju pertapaan. Sinar itu kemudian berubah menjadi cahaya terang dan masuk ke jasad Bratakusumah. Akibatnya Bratakusumah kaget dan merasakan ada keanehan pada dirinya, kemudian ia berucap "Ingsun medangan larang tapa" (Saya silau oleh cahaya di gunung larangan tempat bertapa). Ucapan itu mengakhiri Bratakusumah bertapa.

Selanjutnya Bratakusumah kembali ke keraton dan menceritakan pengalamannya kepada ayah dan keluarganya. Bagi ayahnya, pengalaman Bratakusumah sangat menggembirakan, karena dengan pengalaman itu Bratakusumah bakal mampu mengangkat martabat kerajaan dan rakyat Tembong Agung. Tanggal 14 bulan purnama tahun Saka, Bratakusumah diangkat menjadi raja Tembong Agung menggantikan ayahnya, dengan gelar Prabu Tajimalela $($ Taji $=$ tajam, Malela $=$ selendang $)$.

Prabu Tajimalela menikah dengan Dewi Mayakasih (Dewi Ranggawulung). Dari perkawinan itu lahir tiga orang putra, yaitu Jayabrata, Atmabrata, dan Mariyajaya yang merupakan cikalbakal pembesar Kerajaan Sumedang Larang. Setelah memerintah cukup lama, Prabu Tajimalela lengser sebagai raja, digantikan oleh putranya, Jayabrata dengan gelar Prabu Lembu Agung.

\section{4) Cerita Prabu Lembu Agung}

Garis besar cerita adalah sebagai berikut. Prabu Lembu Agung alias Jayabrata setelah berusia remaja diperintahkan oleh ayahnya untuk belajar ilmu jurus (ilmu bela diri/pencak silat) dan ilmu kebatinan kepada Resi Sakti di Gunung Cakrabuana. Hal itu 
dimaksudkan agar Jayabrata memiliki kekuatan diri sebagai bekal untuk menjadi pemimpin (raja).

Jayabrata diterima oleh Resi Sakti sebagai muridnya dan diwarisi berbagai ilmu. Setelah Jayabrata dianggap cukup menguasai ilmu dari gurunya, sang guru berpesan agar Jayabrata tidak sombong karena memiliki ilmu, dan ilmu itu tidak digunakan semena-mena. Resi Sakti juga menjelaskan bahwa muridnya diberi nama Jayabrata, sesuai dengan citacita ayahnya agar ia kelak menjadi raja yang dapat meningkatkan kejayaan dan kebesaran Kerajaan Tembong Agung.

Selanjutnya Resi Sakti mengizinkan Jayabrata untuk kembali ke keraton. Jayabrata ternyata tidak mengindahkan nasihat gurunya. Dalam perjalanan pulang, ia ingin membuktikan kehebatan ilmu yang telah dimilikinya melalui adu kesaktian. Di suatu kampung, Jayabrata menantang para jawara (pendekar) yang sedang menggelar seni bela diri Ujungan. Dalam waktu singkat ia mampu mengalahkan para jawara. Kemenangan itu menyebabkan Jayabrata menjadi sombong. Ia tidak segera pulang, melainkan berkelana untuk mengadu kesaktian dengan jawara-jawara di berbagai perguruan seni bela diri.

Tindakan Jayabrata itu tersiar ke berbagai daerah, antara lain ke daerah Pagerucukan dan mengusik seorang pendekar bernama Lembu Landak, murid Resi Bangbayang, yang baru selesai bertapa. Lembu Landak mencari Jayabrata dan bertemu di tepi Situ (Danau) Pagerucukan, danau terbesar di wilayah Kerajaan Tembong Agung. Kedua pendekar itu langsung bertarung adu kesaktian. Ternyata Jayabrata kalah, kemudian lari ke Gunung Cakrabuana meminta perlindungan gurunya. Jayabrata mendesak gurunya untuk mewariskan ilmu pamungkas yang disebut Ilmu Tapak Suci, guna mengalahkan Lembu Landak. Ilmu Tapak Suci adalah ilmu pemusnah roh jahat dan pemusnah hawa napsu.

Resi Sakti mengatakan bahwa ilmu tersebut dimiliki oleh ayah Jayabrata, Prabu Tajimalela. Oleh karena itu, Jayabrata segera menuju keraton dan meminta ayahnya mewariskan Ilmu Tapak Suci. Untuk memperoleh ilmu itu, Jayabrata diperintahkan oleh ayahnya melakukan tapabrata di mata air Situ Pagerucukan ${ }^{4}$ selama 40 hari 40 malam.

Ketika Jayabrata sedang bertapa, muncul sosok Resi dan memberi penjelasan, bahwa "Ilmu Tapak Suci hakikatnya adalah kebaikan sejati dalam diri sendiri. Kesucian adalah taat kepada perintah Tuhan. Roh-roh yang telah disucikan oleh Tuhan akan mendampingi, membimbing, dan memberi kekuatan kepada orang yang telah memiliki kesucian dalam dirinya, telah mampu menjauhkan diri dari perbuatan dosa."

Selanjutnya, dari kedua mata Resi keluar sinar kuning. Sinar itu menembus dahi Jayabrata, sehingga ia merasakan adanya keganjilan pada dirinya. Timbul kesadaran yang kuat untuk mengurungkan niat balas dendam terhadap musuhnya (Lembu Landak). Akan tetapi, ketika Jayabrata akan meninggalkan tempat bertapa, muncul Lembu Landak yang langsung menyerangnya. Kali ini Jayabrata berhasil mengalahkan musuhnya. Lembu Landak menyerah dan bersumpah untuk menjadi pengikut Jayabrata. Lembu Landak kemudian diangkat menjadi petinggi di daerah Pagerucukan (Situraja).

4 Menurut cerita, karena peristiwa itulah tempat tersebut kemudian bernama Situraja yang berarti danau besar. 


\section{5) Cerita Prabu Gajah Agung}

Cerita ini mengenai permasalahan suksesi kepemimpinan (tradisi pewarisan tahta kerajaan) yang menyangkut, kearifan, etika, kewajiban pemimpin, dan ajaran kepemimpinan.

Diceritakan bahwa Prabu Tajimalela menghadapi kebingungan dalam mewariskan tahta kerajaan. Hal itu disebabkan ia akan segera lengser dari kedudukannya sebagai raja. Namun ia merasa bingung, kepada putra yang mana tahta itu harus diserahkan, kepada Jayabrata, putra sulung atau kepada adiknya, Atmabrata. Permasalahannya adalah, kedua putranya memiliki hak yang sama untuk menerima tahta kerajaan. Namun Prabu Tajimalela menyadari benar, bahwa mengelola negara harus oleh ahlinya.

Oleh karena itu, dari segi ilmu, Atmabrata lebih layak menerima tahta kerajaan, karena ia menguasai ilmu kepemimpinan. Sebaliknya, Jayabrata lebih menguasai ilmu agama. Akan tetapi, menurut tradisi yang sudah mapan, putra sulung laki-laki memiliki prioritas untuk menerima tahta kerajaan.

Dalam menghadapi masalah tersebut, Prabu Tajimalela bertindak sangat arif. Ia memerintahkan kedua putranya untuk bertapa di Gunung Sangkanjaya, selama 21 hari 21 malam, dengan syarat masing-masing membawa sebuah duwegan (buah kelapa muda). Dijelaskan bahwa setelah selesai bertapa, duwegan itu harus dibelah oleh Pedang Kamkam, senjata pusaka kerajaan. Bila duwegan itu berisi air, pertanda pemiliknya yang berhak menjadi raja.

Ternyata, yang berisi air adalah duwegan milik Atmabrata, sedangkan duwegan milik Jayabrata tidak berair. Berdasarkan simbol itu, Prabu Tajimalela memutuskan Atmabrata menjadi pewaris tahtakerajaan. Putusan itu disetujui secara ikhlas oleh Jayabrata. Namun Atmabrata menolak, karena hal itu melanggar tradisi pewarisan tahta kerajaan.

Jayabrata tidak setuju atas pendirian adiknya, karena sabda raja merupakan hukum yang harus dipatuhi. Perbedaan pendapat itu mengakibatkan terjadinya konflik, bahkan pertarungan kakak lawan adik selama sebulan. Perselisihan kakak beradik itu dapat diatasi oleh Patih Usuro. Prabu Tajimalela sangat menghargai sikap Atmabrata yang tetap hormat kepada sang kakak dan teguh memelihara tradisi kerajaan. Akhirnya Jayabrata menerima putusan bahwa dia lah menjadi raja menggantikan ayahnya. Jayabrata menyatakan "darma ngarajaan". Maksudnya, ia terpaksa menjadi raja memenuhi putusan ayahnya dan persetujuan adiknya.

Sehubungan dengan pernyataan putranya itu, Prabu Tajimalela menjelaskan makna filosofis darma, bahwa darma adalah inti ajaran kepemimpinan. Menurut darma sebagai ajaran, pemimpin yang baik harus mampu menjabarkan ciri-ciri kepemimpinan yang ideal, yaitu tenger, pancer, tanjer, jejer, uger, dan lilinger. Tenger artinya memahami jati diri; pancer maksudnya memiliki kepribadian. Tanjer adalah wawanén (keberanian). Jejer maksudnya pemerintahan yang baik. Uger maksudnya melaksanakan aturan, yaitu aturan-aturan nagara, agama, dan tatali paranti karuhun (tradisi nenek moyang). Lilinger maksudnya pandangan ke masa depan. Filosofi itulah yang ditanamkan oleh Prabu Tajimalela kepada putraputranya. Rupanya mengacu pada kata darma dan pengertiannya itulah, wilayah 
pusat pemerintahan Kerajaan Tembong Agung kemudian disebut Darmaraja.

Diceritakan, Jayabrata dinobatkan menjadi raja Kerajaan Sumedang Larang ${ }^{5}$ dengan gelar Prabu Lembu Agung. Ia beristri Banon Pujasari, masih keturunan PrabuAji Putih. Sementara itu, Atmabrata mendapat perintah dari ayahnya untuk mencari pohon menyan yang tumbuh di tepi sungai. Bila sudah ditemukan, tempat itu harus dibuka menjadi pemukiman. Atmabrata menemukan pohon menyan di tepi Sungai Cipeles. Sesuai dengan perintah ayahnya, Atmabrata membuka daerah itu menjadi pemukiman. Banyak orang dari daerah lain datang ke tempat itu mencari lahan untuk bertani (bersawah atau ngahumal berladang). Mereka mendirikan rumah sederhana sebagai pasanggrahan (tempat istirahat). Itulah sebabnya pemukiman tersebut kemudian bernama Kampung Pasanggrahan, dipimpin oleh Atmabrata sebagai ketua kampung.

Atmabrata tidak lama menjadi ketua kampung, karena diminta oleh kakaknya untuk kembali ke keraton. Setelah kakaknya lengser dari kedudukannya sebagai raja, pemerintahan kerajaan dilanjutkan oleh Atmabrata dengan gelar Prabu Gajah Agung.

\section{6) Cerita Tentang Asal-usul Nama Tempat}

Cerita-cerita yang telah dikemukakan menyinggung asal-usul nama tempat. Mengenai asal-usul nama tempat juga disinggung dalam cerita-

5 Maksudnya adalah raja Kerajaan Tembong Agung, karena dalam sumbersumber sejarah tidak ada raja Sumedang Larang yang bernama/bergelar Prabu Lembu Agung. cerita lain. Misal, asal-usul Kampung Ciwangi disinggung dalam cerita Dalem Santapura. Asal-usul mata air Cipawenang termuat dalam cerita Nyai Ratu Asih Ranca Omas, dan lain-lain.

Diceritakan bahwa Santapura adalah putra Prabu Lembu Agung. Santapura diperintahkan oleh ayahnya untuk menguasai ilmu kedarmarajaan, yaitu ilmu kepemimpinan dan ilmu-ilmu lain, termasuk ilmu kebatinan, sebagai bekal kelak ketika menjadi raja. Untuk menyempurnakan ilmunya, Santapura harus bertapa selama belasan hari di tepi Sungai Cimanuk daerah Cipeueut (Lemah Sagandu). Ia bertapa di bawah pohon tanjung yang telah berusia ratusan tahun.

Selesai bertapa, Santapura menancapkan tongkat di bawah pohon tanjung. Aneh bin ajaib, seketika itu pula pada tancapan tongkat itu keluar air. Lama kelamaan mata air itu menjadi sumur dan airnya seungit (wangi, harum). Sehubungan dengan hal itu, Santapura berucap "Nyeungitan di Ciwangi mancuhkeun di Cipaku."

Selanjutnya di tempatitu Santapura mendirikan padepokan (pesantren). Banyakorangdatanguntukbergurukepada Santapura dan menetap di sana. Lama kelamaan tempat itu menjadi pemukiman yang disebut Kampung Ciwangi. Mereka membuka lahan pertanian, sehingga Kampung Ciwangi dan Cipaku menjadi "lumbung" padi, karena adanya air dari sumur Ciwangi yang tidak pernah surut. Berdasarkan cerita itu, masyarakat setempat menganggap mata air Ciwangi mengandung kekuatan magis.

Tempat lain yang dikeramatkan adalah mata air Cipawenang di Kampung Cigangsa, Desa Pawenang, Kecamatan Wado. Seperti telah disebutkan, nama 
daerah mata air itu disebut dalam cerita Nyai Ratu Asih Ranca Omas. Menurut cerita rakyat yang turun-temurun, tokoh dalam cerita itu adalah putri dari Kerajaan Nunuk (daerah Majalengka). Ia dilamar oleh beberapa orang raja. Dengan bijaksana, Nyai Ratu Asih menolak semua lamaran, dengan pertimbangan, bila lamaran salah seorang raja diterima, khawatir akan mengakibatkan terjadinya perang antara beberapa kerajaan dengan Kerajaan Nunuk. Oleh karena itu, ia memutuskan untuk berkelana ke daerah lain.

Dalam perjalanan menuju daerah Sumedang, Nyai Ratu Asih merasa haus, sedangkan ia tidak membawa bekal air minum dan di tempat ia beristirahat tidak ada air. Oleh karena itu, ia segera mengheningkan cipta, memohon keajaiban dari Sang Maha Kuasa. Selesai mengheningkan cipta, di tempat itu keluar air yang sangat jernih. Air itu keluar terus-menerus sehingga menjadi sumber air bagi kehidupan masyarakat. Terhadap daerah mata air itu ada warga masyarakat yang menyebut Cipawenang, dan ada pula yang menyebut Ciptawenang atau Ciptawening. Sekarang tempat itu menjadi Situs Cipawenang.

Dalam kehidupan masyarakat daerahsetempat,mataairitudikeramatkan karena dianggap mengandung unsur magis yang membawa berkah. Oleh karena itu, bila para petani akan mengolah sawah untuk menanam padi, sawah mereka terlebih dahulu disiram dengan air dari mata air tersebut. Sebelum mulai melakukan kegiatan pertanian, khususnya bersawah, para petani terlebih dahulu berdoa di sekitar situs, kemudian makan tumpeng. Kegiatan itu menjadi tradisi yang turun-temurun. Katanya, dengan tradisi itu, sawah menjadi subur dan padi atau tanaman lainnya terbebas dari serangan hama.

Bila cerita-cerita yang berkaitan dengan situs dikaji secara saksama, di dalamnya terkandung nilai-nilai tradisional yang antara lain memiliki makna pembelajaran. Cerita tertentu juga mengandung unsur dan nilai sastra yang cukup menarik untuk dikaji.

\section{PENUTUP}

Meskipun data kesejarahan situssitus di Jatigede masih merupakan data lemah, akan tetapi masyarakat setempat sangat mempercayai keterkaitan situs dengan sejarah Sumedang. Oleh karena itu, situs-situs tersebut memiliki makna sejarah dan sekaligus makna budaya. Dalam perpaduan kedua makna itulah letak nilai situs Jatigede.

Berdasarkan data yang dimilikinya, situs-situs itu merupakan peninggalan peradaban manusia tempo dulu yang mencakup zaman prasejarah dan zaman sejarah (Hindu dan Islam). Dengan kata lain, peninggalan peradaban itu memperlihatkan adanya transformasi budaya dari zaman prasejarah ke zaman sejarah. Dalam hal ini, makammakam kuno yang bercirikan megalitik, merupakan warisan budaya prasejarah yang diterapkan pada zaman sejarah.

Keberadaan sejumlah situs di Jatigede yang sebagian besar berupa makam kuno yang dianggap keramat, sudah diketahui oleh masyarakat luas, bukan saja oleh warga masyarakat Sumedang, tetapi juga warga masyarakat di luar Sumedang maupun Jawa Barat. Hal ini menyebabkan berkembangnya budaya wisata ziarah ke makammakam di situs-situs tertentu. Kondisi ini mengandung arti, bahwa situs-situs 
tersebut merupakan aset wisata yang perlu dilestarikan.

Apabila seluruh atau sebagian situs itu ditenggelamkan atau direlokasi ke tempat lain sejalan dengan pembangunan Waduk Jatigede, maka makna dan nilai sejarah dan mungkin juga makna atau nilai budayanya akan turut hilang atau setidaknya berkurang. Hal itu disebabkan karena kesejarahan dan kebudayaan selalu berkaitan dengan tempat (site) dan benda di dalamnya.

\section{DAFTAR SUMBER}

\section{Buku/Artikel/Internet}

Anonim. tt.

"Mega Proyek Pembangunan Waduk Jatigede", terbaca dalam http:// sumedang.go.id/files/ perda/MEGA\%20PROYEK\%20 JATIGEDE.pdf

-------. 1996.

Mengenal Museum Prabu Geusan Ulun serta Riwayat Leluhur Sumedang.

Jawa Barat, Pemerintah Propinsi. 2007. Laporan Pendahuluan Identifikasi Artefaktual, Kontekstual, dan Historikal Situs-Situs di Wilayah Eks Genangan Waduk Jatigede di Kabupaten Sumedang. Dinas Pengelolaan Sumberdaya Air.

Kartadibrata, Abdullah. 1989.

Brosur Museum Prabu Geusan Ulun Sumedang. Cetakan ke-2. Sumedang: t.p.
Keesing, Roger M. 1997.

"Teori-Teori tentang Budaya", dalam Antropologi Indonesia (52): 4-32.

Lubis, Nina Herlina. tt.

"Mengenal Situs Jati Gede", terbaca dalam http://www.mailarchive.com/baraya_sunda@ yahoogroups.com/msg00725.html.

2008.

Sejarah Sumedang dari Masa ke Masa. Sumedang: Dinas Pariwisata dan Kebudayaan Kabupaten Sumedang.

Saringendyanti, Etty. 2008.

Tinggalan Budaya di Situs Jatigede (Sumedang) dalam Perspektif Arkeologi. Bandung

Suganda, Her. 2004.

"Darmaraja Pernah Jadi Pusat Kerajaan", terbaca dalam http:// www2.kompas.com/kompascetak/0411/01/Jendela/1355555. htm.

Surianingrat, Bayu. 1983.

Sejarah Kabupaten I Bhumi Sumedang 1550 - 1950. Tanpa penerbit.

\section{Informan}

1. Darmawan Ider Alam, tokoh masyarakat Jatigede, Sumedang.

2. Hendra Sonawijaya, pengelola Museum Prabu Geusan Ulun.

3. Wikarta, kuncen Situs Tanjungsari. 